\title{
Effectiveness of adjuvant chemotherapy for elderly patients with lymph node-positive colorectal cancer
}

\author{
Tetsuro Tominaga ${ }^{1 *}$ D, Takashi Nonaka', Yorihisa Sumida', Shigekazu Hidaka', Terumitsu Sawai ${ }^{2}$ \\ and Takeshi Nagayasu ${ }^{1}$
}

\begin{abstract}
Background: Several guidelines state that postoperative adjuvant chemotherapy (AC) confers survival benefits to patients with lymph node-positive colorectal cancer. However, older patients are usually not administered AC due to the higher risk of side effects. The aim of this study was to evaluate the benefit of AC for elderly patients (EP) and examine its tolerability.
\end{abstract}

Methods: Data from 204 patients with lymph node-positive colon cancer were retrospectively analyzed. Patients were subdivided into two groups: EP, $>75$ years old $(n=53)$ and young patients (YP), $<75$ years old $(n=151)$. Clinicopathological features, type of chemotherapy, and outcomes were compared between groups.

Results: Frequency of comorbidities and performance status were significantly higher in EP ( $p<0.01$ each), a greater proportion of YP $(76 \%)$ than EP received AC (40\%, $p<0.01)$, and YP received combination therapy more frequently than EP $(p<0.01)$. In terms of side effects, few EP showed severe side effects. Both YP and EP gained survival benefits from $\mathrm{AC}(p=0.07$ and $p<0.01$, respectively).

Conclusions: AC should not be withheld from eligible EP purely because of age.

Keywords: Adjuvant chemotherapy, Colorectal cancer, Elderly patients

\section{Background}

Colorectal cancer is one of the most common cancers worldwide, with an incidence of 1.2 million per year globally [1]. Generally, as the population ages, the incidence of elderly colorectal cancer patients is likely to increase.

According to the tumor-node-metastasis system, colorectal cancer with lymph node metastasis is defined as stage III disease [2]. About $50 \%$ of patients with stage III cancer reportedly experience disease recurrence, such as local recurrence or distant metastasis, and the 5-year survival rate is $68-77 \%[3,4]$. In the 1990 s, the concept of adjuvant chemotherapy (AC) after curative resection for patients with stage III colon cancer was established to improve long-term outcomes [5]. AC can reportedly result in a $30 \%$ decrease in relapse rates compared with

\footnotetext{
* Correspondence: tomitetsu2000@yahoo.co.jp

${ }^{1}$ Department of Surgical Oncology, Nagasaki University Graduate School of Biomedical Science, 1-7-1 Sakamoto, Nagasaki 852-8501, Japan Full list of author information is available at the end of the article
}

surgery alone. Furthermore, several randomized controlled studies have revealed that stage III colon cancer patients benefit in terms of both relapse-free survival and overall survival using combination therapies that include oxaliplatin [6, 7].

However, not all patients with stage III colon cancer receive postoperative $\mathrm{AC}$, with such treatment withheld from 48 to $77 \%$ of colon cancer cases [8-10]. In general, elderly patients (EP) display higher rates of comorbidities, including cardiovascular disease, diabetes mellitus, and pulmonary disease, than younger patients (YP) [11-13]. As EP may experience a higher rate of side effects compared to YP, the decision to start postoperative AC for EP should be made carefully [9]. The Adjuvant Colon Cancer End Points (ACCENT) group assembled patient data from 18 trials testing fluoropyrimidine-based AC for patients with stage II or III colorectal cancer. Previous analyses of data from ACCENT comparing surgery alone with surgery followed by fluorouracil-based $\mathrm{AC}$ have revealed that 
patients $\geq 70$ years old experienced similar benefits from AC compared with YP $[14,15]$. However, another study revealed that EP seemed to gain reduced benefit from the addition of oxaliplatin to fluoropyrimidine in the adjuvant setting.

The aim of this study was to evaluate the effectiveness of AC for EP with colorectal cancer. We also examined the features of selected chemotherapeutic agents and their tolerability.

\section{Methods}

\section{Patients}

The institutional review board approved this retrospective observational study. Informed consent was obtained from all patients prior to surgery.

From January 2005 to December 2014, a total of 790 colorectal cancer patients underwent colorectal resection of the primary cancer in the Department of Surgical Oncology at Nagasaki University Graduate School of Biological Sciences. Among these, 215 patients were diagnosed with lymph node-positive colon cancer based on histopathological examination. Although neoadjuvant chemotherapy (NAC) is usually administered to patients with locally advanced colorectal cancer, the present study excluded 11 patients who received NAC to avoid confounding effects on AC. As a result, data were obtained for a final total of 204 patients with lymph node-positive colon cancer. These patients were subdivided into two groups: EP, $\geq 75$ years old $(n=53)$ and YP, $<75$ years old $(n=151)$.

Before surgery, the appropriateness of resection was determined by abdominal CT and colonoscopy. The following data were retrospectively collected: age, sex, performance status, tumor markers including CEA and CA19-9, International Union Against Cancer tumor stage, operation time, blood loss, and postoperative data (including pathology, lymphatic and vessel invasion, depth of tumor invasion, hospital stay, and 30-day morbidity and mortality rates). Postoperative complications were graded according to the Clavien-Dindo classification categorizing surgical complications from grades 1 to 5 , based on the invasiveness of the treatment required. In the present study, complications were defined as conditions that required treatment (Clavien-Dindo classification grades 2-5).

Colectomy, anterior resection, and abdominoperineal resection plus lymph node resection were performed according to the guidelines of the Japanese Society for Cancer of the Colon and Rectum. Either hand-sewn anastomosis or end-to-end anastomosis using a doublestapling technique was performed, depending on tumor location. Mortality and morbidity data were collected from the databases of our department and collaborating hospitals.
$A C$

AC was started within 4-8 weeks after surgery, using 5fluorouracil, TS-1, or capecitabine as a single-agent chemotherapy or oxaliplatin, 5-fluorouracil, and folinic acid (FOLFOX), S-1 and oxaliplatin (SOX), or capecitabine and oxaliplatin (XELOX) as a combination therapy. The side effects were graded according to Common Terminology Criteria for Adverse Events version 4.0.

\section{Statistical analysis}

Data from the different groups were compared using Student's $t$ test. Continuous data are expressed as mean \pm standard deviation (SD). On univariate analysis, comparisons of categorical variables were performed using the chi-square test or Fisher's exact test. Values of $p<$ 0.05 were considered significant. Overall and diseasefree survival rates were calculated according to KaplanMeier methods. Differences between groups were tested for significance using the log-rank test. All statistical analyses were performed using SPSS version 22 software (SPSS, Chicago, IL).

\section{Results}

\section{Clinicopathological features and parameters}

Table 1 shows the characteristics of each group. Sex, age, body mass index, tumor location, tumor type, tumor size, lymph node metastasis, and concentrations of tumor markers, including CEA and CA19-9, did not differ significantly between groups. Frequency of comorbidities and performance status were significantly higher in EP than in YP $(p<0.01$ each). A number of patients who had hypertension, cardiac disease, or brain infarction were identified among EP.

\section{Surgical features and outcomes}

Lymphatic invasion was significantly more frequent in EP than in YP $(p=0.02)$. No significant differences in histological type, vessel invasion, operation time, blood loss, operative procedures, or combined resection were seen between groups. Postoperative complications and length of hospital stay likewise did not differ between groups. Among YP, 76 \% (115/151) had received AC, compared to only $40 \%(21 / 52)$ among EP $(p<0.01$; Table 2).

\section{Types of AC}

Among YP who received AC, $62 \%$ (71/115) received single-agent chemotherapy (TS-1, $n=29$; tegafur-uracil, $n=33$; capecitabine, $n=9)$ and $38 \%(44 / 115)$ received combination therapy (FOLFOX, $n=19$; SOX, $n=14$; XELOX, $n=11)$. On the other hand, among EP, $71 \%$ $(15 / 21)$ were administered single-agent chemotherapy (TS-1, $n=3$; tegafur-uracil, $n=11$; capecitabine, $n=1$ ) and only $29 \%(6 / 21)$ received combination therapy 
Table 1 Relationship between patient age and clinicopathological features

\begin{tabular}{|c|c|c|c|}
\hline & Age $<75$ years & Age $\geq 75$ years & $p$ \\
\hline$n$ & 151 & 53 & \\
\hline Age, years & $61(30-74)$ & $81(75-94)$ & \\
\hline Sex (male/female) & 85 (56.3 \%)/66 (43.7\%) & $24(45.3 \%) / 29(54.7 \%)$ & 0.16 \\
\hline Body mass index $\left(\mathrm{kg} / \mathrm{m}^{2}\right)$ & 23.3 & 23.5 & 0.91 \\
\hline Co-morbidity (no/yes) & 91 (60.3 \%)/60 (39.7\%) & $18(40.0 \%) / 35(60.0 \%)$ & $<0.01$ \\
\hline Hypertension & 20 & 13 & \\
\hline Diabetes mellitus & 12 & 3 & \\
\hline Respiratory disease & 6 & 3 & \\
\hline Heart disease & 6 & 6 & \\
\hline Renal disease & 5 & 3 & \\
\hline Brain infarction & 5 & 4 & \\
\hline Connective tissue disease & 3 & 2 & \\
\hline Liver disease & 3 & 1 & \\
\hline Performance status $(0,1 / 2,3)$ & 137 (90.7 \%)/14 (9.3 \%) & 38 (71.7 \%)/15 (28.3 \%) & $<0.01$ \\
\hline Location (C/A/T/D/S/R) & $\begin{array}{l}8(5.3 \%) / 18(11.9 \%) / 10(6.6 \%) / 8(5.3 \%) / 34(22.5 \%) / 73 \\
(48.4 \%)\end{array}$ & $\begin{array}{l}4(7.5 \%) / 12(22.6 \%) / 5(9.4 \%) / 3(5.7 \%) / 12(22.6 \%) / 17 \\
(32.2 \%)\end{array}$ & 0.28 \\
\hline Tumor type $(0 / 1 / 2 / 3 / 4 / 5)$ & $\begin{array}{l}17(11.3 \%) / 25(16.6 \%) / 94(62.2 \%) / 13(8.7 \%) / 1(0.6 \%) / \\
1(0.6 \%)\end{array}$ & 1 (1.9\%)/7 (13.2 \%)/38 (71.7\%)/6 (11.3\%)/0/1 (1.9\%) & 0.26 \\
\hline Tumor size $(\mathrm{mm})$ & $69(9-103)$ & $47(9-87)$ & 0.36 \\
\hline $\begin{array}{l}\text { Tumor depth } \\
\text { (m/sm/mp/ss/se/ai) }\end{array}$ & $\begin{array}{l}\text { 0/2 (1.3\%)/19 (12.6\%)/108 (71.5\%)/12 (7.9\%)/10 } \\
(6.7 \%)\end{array}$ & 0/2 (3.8 \%)/4 (7.5 \%)/37 (69.8 \%)/7 (13.2 \%)/3 (5.7\%) & 0.74 \\
\hline $\begin{array}{l}\text { Lymph node metastasis } \\
\text { (N1/2/3) }\end{array}$ & $98(64.9 \%) / 38(25.2 \%) / 15$ (9.9 \%) & $34(64.2 \%) / 13(24.5 \%) / 6(11.3 \%)$ & 0.95 \\
\hline CEA & 8.1 & 9.1 & 0.69 \\
\hline CA19-9 & 26.1 & 21.4 & 0.97 \\
\hline
\end{tabular}

(FOLFOX, $n=4$; SOX, $n=1$; XELOX, $n=1$ ). Significant differences were evident between groups in the selection of chemotherapeutic agents $(p<0.01)$ (Table 3$)$.

\section{Tolerability of chemotherapy}

Thirteen of the 71 YP (18.3\%) who received singleagent chemotherapy experienced side effects of grade 3 or greater, compared to 19 of $44 \mathrm{YP}$ patients (43.2\%) who received combination therapy (median follow-up period, 35 vs. 51 months, respectively). On the other hand, none of the EP who received single-agent chemotherapy experienced severe side effects (0\%), compared to $\operatorname{EP}(33.3 \%)$ who received combination therapy. In both groups, neutropenia was the most frequent side effect in this study. In YP, AC with single/combination agents was discontinued in eight of 71 patients $(11.3 \%)$

Table 2 Relationship between tumor and surgical features and outcomes

\begin{tabular}{llll}
\hline & Age $<75$ years & Age $\geq 75$ years & $p$ \\
\hline Histological grade (well/mod/poor) & $54(35.8 \%) / 83(55.0 \%) / 14(9.2 \%)$ & $19(35.8 \%) / 28(52.8 \%) / 6(11.4 \%)$ & $6(11.3 \%) / 47(88.7 \%)$ \\
Lymphatic invasion (no/yes) & $6(4.0 \%) / 145(96.0 \%)$ & $7(13.2 \%) / 46(86.8 \%)$ & 0.99 \\
Vessel invasion (no/yes) & $20(13.2 \%) / 131(86.8 \%)$ & $241(74-645)$ & 0.02 \\
Operation time (min) & $480(80-713)$ & $129(20-510)$ & 0.99 \\
Blood loss (g) & $185(10-1400)$ & $31(58.5 \%) / 22(41.5 \%)$ & 0.35 \\
Laparoscopic surgery (no/yes) & $83(55.0 \%) / 69(45.0 \%)$ & $48(90.6 \%) / 5(9.4 \%)$ & $32(60.4 \%) / 21(39.6 \%)$ \\
Composite resection (no/yes) & $143(94.7 \%) / 8(5.3 \%)$ & $32(60.4 \%) / 21(39.6 \%)$ & 0.07 \\
Postoperative chemotherapy (no/yes) & $36(23.8 \%) / 115(76.2 \%)$ & $25.5(16-40)$ & 0.38 \\
Postoperative complication (no/yes) & $95(62.9 \%) / 56(37.1 \%)$ & & 0.74 \\
Hospital stay (days) & $25.7(14-31)$ & & 0.93 \\
\hline
\end{tabular}


Table 3 Types of postoperative chemotherapy

\begin{tabular}{llll}
\hline & Age $<75$ years & Age $\geq 75$ y & $p$ value \\
$n$ & 115 & 21 & \\
\hline Single agent & 71 & 15 & $<0.01$ \\
Combination therapy & 44 & 6 & \\
FOLFOX & 19 & 4 & \\
SOX & 14 & 1 & \\
XELOX & 11 & 1 & \\
TS-1 & 29 & 3 & \\
UFT & 33 & 11 & \\
Capecitabine & 9 & 1 & \\
\hline
\end{tabular}

UFT 5-fluorouracil, oxaliplatin, FOLFOX 5-fluorouracil, and folinic acid, SOX S-1 and oxaliplatin, XELOX capecitabine plus oxaliplatin

and six of 44 patients (13.6\%), respectively. On the other hand, in EP, AC with single/combination agents was discontinued in one of 15 patients (6.7 \%) and none of six patients (0\%) (Table 4). During the observation period, one patient in the YP group who received mFOLFOX6 died due to acute pneumonia.

\section{Kaplan-Meier curves of the effect of chemotherapy on disease-free and overall survival}

YP showed no significant differences in disease-free survival between chemotherapy and non-chemotherapy subgroups $(p=0.35)$, and while overall survival tended to be better in the chemotherapy subgroup, the effect

Table 4 Side effects and incidence of discontinuation of therapy in patients who received adjuvant chemotherapy

\begin{tabular}{|c|c|c|c|c|}
\hline \multirow[b]{3}{*}{$n$} & \multicolumn{2}{|c|}{ Age $<75$ years } & \multicolumn{2}{|c|}{ Age $>75$ years } \\
\hline & Single & Combination & Single & Combination \\
\hline & 71 & 44 & 15 & 6 \\
\hline $\begin{array}{l}\text { Side effects } \geq \text { grade } \\
3\end{array}$ & $\begin{array}{l}13 \\
(18.3 \%)\end{array}$ & $19(43.1 \%)$ & $0(0 \%)$ & $2(33.3 \%)$ \\
\hline \multicolumn{5}{|l|}{ Signs and symptoms } \\
\hline Neutropenia & 3 & 9 & 0 & 2 \\
\hline Anorexia & 3 & 3 & 0 & 0 \\
\hline Diarrhea & 3 & 2 & 0 & 0 \\
\hline Pneumonia & 0 & 1 & 0 & 0 \\
\hline Anaphylaxis & 0 & 1 & 0 & 0 \\
\hline General fatigue & 0 & 1 & 0 & 0 \\
\hline Perforation & 0 & 1 & 0 & 0 \\
\hline $\begin{array}{l}\text { Acute } \\
\text { leukoencephalopathy }\end{array}$ & 0 & 1 & 0 & 0 \\
\hline Liver dysfunction & 1 & 0 & 0 & 0 \\
\hline $\begin{array}{l}\text { Hand-foot } \\
\text { syndrome }\end{array}$ & 1 & 0 & 0 & 0 \\
\hline Hyperbilirubinemia & 2 & 0 & 0 & 0 \\
\hline Discontinuation & $8(11.3 \%)$ & $6(13.6 \%)$ & $\begin{array}{l}1 \\
(6.7 \%)\end{array}$ & $0(0 \%)$ \\
\hline
\end{tabular}

was still not significant $(p=0.07)$ (Fig. 1a). Likewise in EP, no significant difference in disease-free survival was evident between chemotherapy subgroups $(p=0.47)$. However, overall survival was significantly better in the chemotherapy subgroup $(p=0.01)$ (Fig. 1b).

\section{Discussion}

Although the proportion of patients receiving $\mathrm{AC}$ was much lower among EP than among YP, the present results suggest that postoperative AC might be effective for improving overall survival in EP. In addition, the entire course of $\mathrm{AC}$ was able to be completed in many $\mathrm{EP}$ without severe side effects.

Previous studies have revealed the survival benefits of postoperative AC for patients with stage III colorectal cancer [16-18]. However, emphasis has been placed on careful diligence in assessing the indications for $\mathrm{AC}$ in $E P$, since these patients often show low performance status, major organ dysfunction, and high frequencies of comorbidities $[19,20]$. In the present study, the frequency of comorbidities was higher and performance status was lower in EP than in YP ( $p<0.01$ each).

In the 1990s, the rate of administering AC was reportedly lower in EP (10-32 \%) than in YP (55-77 \%) [9, 10]. Ko and colleagues recently examined data from 810 colorectal cancer patients with lymph node metastasis [1]. They revealed that $\mathrm{AC}$ tended to be administered less frequently to EP (57\%) than to YP (91\%), as previously reported, even though the benefits of AC have been widely recognized. Furthermore, combination therapy was selected less often for EP (32\%) than for YP (74 \%). In our study, the proportion of patients receiving AC was lower among EP (21/52, $40 \%)$ than among YP (115/151, $76 \%)$. In addition, the frequency of administering combination therapy was significantly lower in EP $(28.6 \%)$ than in YP $(38.2 \%, p<0.01)$. The most common reason for withholding AC from EP was identified as patient age (15/32; $47 \%$ ) (Additional file 1: Table S1). In the YP group, $\mathrm{AC}$ was most often withheld from patients due to patient choice $(15 / 36 ; 42 \%)$. Such findings are supported by the results of a previous report on reasons for withholding AC [21].

Some studies have revealed that EP are at increased risk of developing side effects, such as nausea, stomatitis, vomiting, and neutropenia [9, 22-25]. However, other investigations have indicated that the rate of side effects does not differ between EP and YP [26, 27]. In a randomized trial involving 1014 patients, incidences of neutropenia, gastrointestinal toxic effects, and dermatitis were not significantly different between different age groups [28]. In our study, the rate of AC completion was high in the EP group, and the incidence of side effects of grade 3 or greater was lower in EP than in YP. Although our study may have involved some degree of selection 

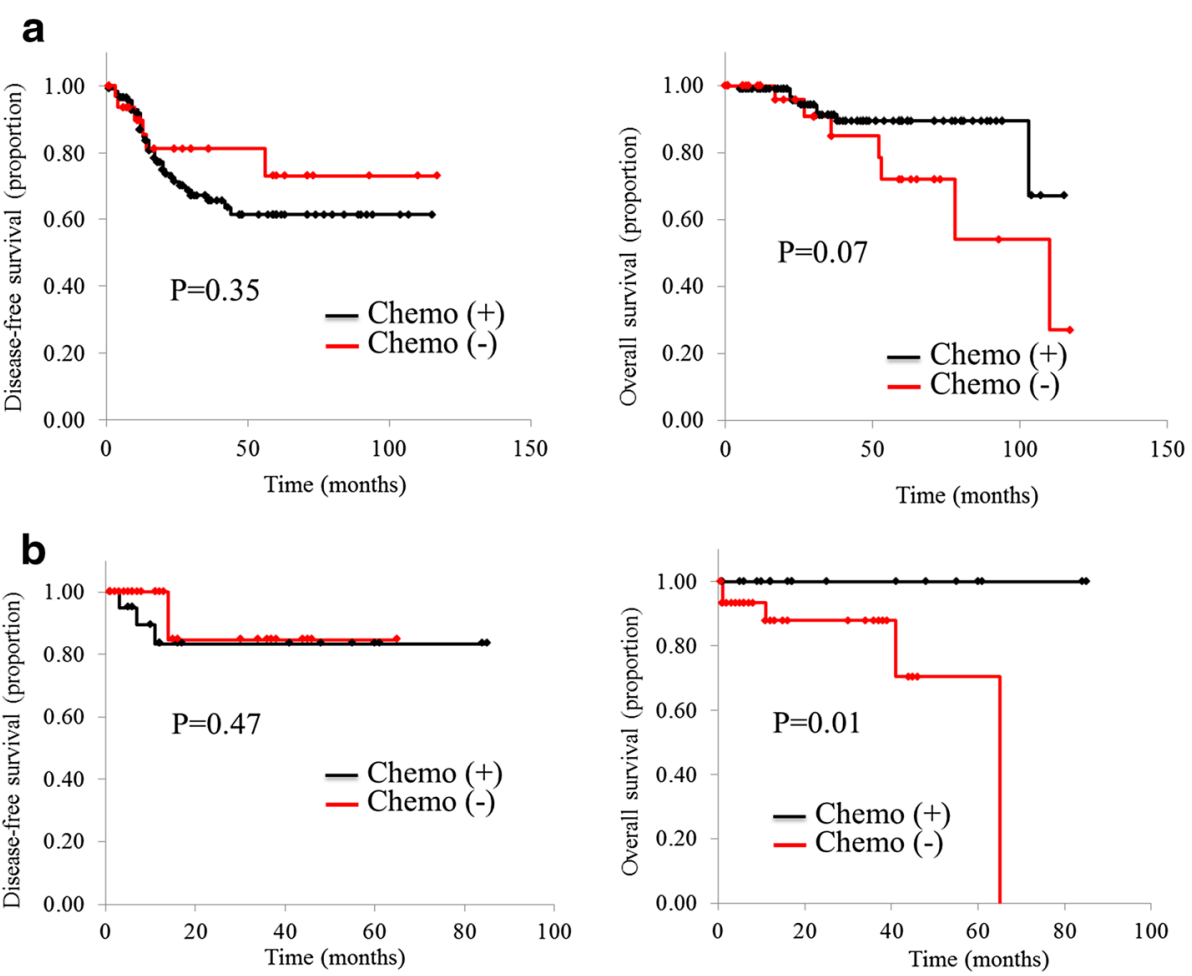

Fig. 1 Disease-free survival and overall survival of stage III colorectal cancer patients. The subgroup of patients who received adjuvant chemotherapy displayed improved survival outcomes for both younger patients $(p=0.07 ; \mathbf{a})$ and elderly patients $(p=0.01 ; \mathbf{b})$

bias, since we made deliberate choices in terms of performance status, general status, and cognitive function, particularly in EP, our results suggest that EP can safely receive postoperative $\mathrm{AC}$ if the selection of therapy is appropriate.

Steinberg and colleagues examined 1296 colorectal cancer patients with local invasion or positive lymph nodes [26]. They compared groups with and without AC and found significantly lower cancer recurrence and overall death rates in the AC group. Other studies have likewise revealed benefits in terms of disease-free survival and overall survival from the use of postoperative AC [27-30]. In the present study, in both YP and EP, overall survival was better among patients who received AC than among those who only underwent surgery ( $p=0.07$ and $p=0.01$, respectively). Sanoff and colleagues examined the effects of AC in 5489 colorectal cancer patients 75 years of age and older [31]. They reported that the incidence of AC administration declined with patient age. They also indicated that EP could gain survival benefits from AC (hazard ratio, 0.60; $95 \% \mathrm{CI}$, 0.53-0.68), supporting the present results. Other randomized clinical trials have also revealed that AC offers improved disease-free and overall survival in colorectal cancer patients over 70 years of age [32-34]. About $40 \%$ of colorectal cancer patients are reportedly over 75 years old [35], yet older patients remain underrepresented in clinical trials of chemotherapy because of the scarcity of efficacy data
[32]. In the future, steps should be taken to ensure greater inclusion of older patients in such clinical trials.

Chronological age reportedly does not correlate with physiological age [36-39]. However, many older people are not provided AC because of their advanced chronological age (Additional file 1: Table S1) [1]. Several geriatric assessment tools that could help predict patient outcomes are now available [40-42]. Hurria and colleagues also revealed a predictive model of chemotherapy toxicity for older patients, and application of such tools should be considered when selecting chemotherapies for older patients [43]. A previous report revealed that $29 \%$ of colorectal cancer patients older than 70 years died due to disease recurrence, while $13 \%$ died due to causes unrelated to recurrence [9]. These results indicate that appropriate chemotherapy in older patients might confer a survival benefit in terms of cancer control, and clinicians should thus not hesitate to aggressively treat cancers in EP, just as in YP.

The main drawback of this study was the selection bias, in that only patients fit for chemotherapy were administered treatment. Thus, definition of the circumstances in which chemotherapy may be selected for node-positive patients who are elderly is paramount. A randomized controlled trial is more likely to yield an adequate assessment of whether EP should be administered $\mathrm{AC}$ under strict selection criteria. 


\section{Conclusions}

The present findings suggest that postoperative $\mathrm{AC}$ could be effective in improving overall survival following resection of stage III colorectal cancer, not only in YP but also in EP. AC should therefore not be withheld from eligible EP purely on the basis of advanced age.

\section{Additional file}

Additional file 1: Table S1. Reasons for withholding adjuvant

chemotherapy. (DOC 46 kb)

\section{Abbreviations}

AC, adjuvant chemotherapy; NAC, neoadjuvant chemotherapy

\section{Acknowledgements}

Not applicable

\section{Funding}

There is no funding support.

\section{Availability of data and material}

Not applicable

\section{Authors' contributions}

TT and TN carried out the surgery. YS and SH participated in the design of this study. TS performed the statistical analyses. TN conceived of the study, participated in its design and coordination, and helped to draft the manuscript. All authors read and approved the final manuscript.

\section{Competing interests}

The authors declare that they have no competing interests.

\section{Consent for publication}

We have obtained consent for publication from patients.

Ethics approval and consent to participate

Not applicable

\section{Author details}

${ }^{1}$ Department of Surgical Oncology, Nagasaki University Graduate School of Biomedical Science, 1-7-1 Sakamoto, Nagasaki 852-8501, Japan. ${ }^{2}$ Department of Cardiopulmonary Rehabilitation Science, Nagasaki University Graduate School of Biomedical Science, 1-7-1 Sakamoto, Nagasaki 852-8501, Japan.

Received: 5 May 2016 Accepted: 22 July 2016

Published online: 28 July 2016

\section{References}

1. Ko JJ, Kennecke HF, Lim HJ, Renouf DJ, Gill S, Woods R, Speers C, Cheung WY. Reasons for underuse of adjuvant chemotherapy in elderly patients with stage III colon cancer. Clin Colorectal Cancer. 2015;15:179-85.

2. Greene FL, Page DL, Fleming ID, Fritz AG, Balch CM, Haller DG. AJCC cancer staging manual. 6th ed. Philadelphia: Springer; 2002.

3. O'Connell JB, Maggard MA, Ko CY. Colon cancer survival rates with the new American joint committee on cancer sixth edition staging. J Natl Cancer Inst. 2004;96:1420-5.

4. Japanese society for cancer of the colon and rectum: multi-institutional registry of large bowel cancer in Japan. Vol. 30 cases treated in 2003-2004 Published in October 2012.

5. NIH consensus conference. Adjuvant therapy for patients with colon and rectal cancer. JAMA. 1990;264:1444-50.

6. Andre T, Boni C, Mounedii-Boudiaf L, Navarro M, Tabernero J, Hickish T, Topham C, Zaninelli M, Clingan P, Bridgewater J, Tabah-Fisch I, de Gramont A, Multicentre International Study of Oxaliplatin/5-Fluorouracil/Leucovorin in the Adjuvant Treatment of Colon Cancer (MOSAIC) Investigators. Oxaliplatin, fluorouracil, and leucovorin as surgical adjuvant treatment of colon cancer. N Engl J Med. 2004;350:2343-51.
7. Kuebler JP, Wieand HS, O'Connell MJ, Smith RE, Colangelo LH, Yothers G, Petrelli NJ, Findlay MP, Seay TE, Atkins JN, Zapas JL, Goodwin JW, Fehrenbacher L, Ramanathan RK, Conley BA, Flynn PJ, Soori G, Colman LK, Levine EA, Lanier KS, Wolmark N. Oxaliplatin combined with weekly bolus fluorouracil and leucovorin as surgical adjuvant chemotherapy for stage II and III colon cancer: result from NSABP C-07. J Clin Oncol. 2007;25:2198-204.

8. Schrag D, Cramer LD, Bach PB, Begg CB. Age and adjuvant chemotherapy use after surgery for stage III colon cancer. J Natl Cancer Inst. 2001;93:850-7.

9. Sargent DJ, Goldberg RM, Jacobson SD, Macdonald JS, Labianca R, Haller DG, Shepherd LE, Seitz JF, Francini G. A pooled analysis of adjuvant chemotherapy for resected colon cancer in elderly patients. N Engl J Med. 2001;15:1091-7.

10. Sundararajan V, Mitra N, Jacobson JS, Grann VR, Heitjan DF, Neugut Al. Survival associated with 5-fluorouracil-based adjuvant chemotherapy among elderly patients with node-positive colon cancer. Ann Intern Med. 2002:136:349-57.

11. Alves A, Panis Y, Mathieu P, Mantion G, Kwiatkowski F, Slim K. Postoperative mortality and morbidity in French patients undergoing colorectal surgery: result of a prospective multicenter study. Arch Surg. 2005;140:278-83.

12. Fielding LP, Phillips RK, Hittinger R. Factors influencing mortality after curative resection for large bowel cancer in elderly patients. Lancet. 1989; 8638:595-7.

13. Turrentine FE, Wang H, Simpson VB, Jones RS. Surgical risk factors, morbidity, and mortality in elderly patients. J Am Coll Surg. 2006;203:865-77.

14. Sargent DJ, Goldberg RM, Jacobson SD, Macdonald JS, Labianca R, Haller DG, Shepherd LE, Seitz JF, Francini G. A pooled analysis of adjuvant chemotherapy for resected colon cancer in elderly patients. N Engl J Med. 2001;345:1091-7.

15. McCleary NJ, Meyerhardt J, Green E, Yothers G, de Gramont A, Cutsem EV, O'Connel M, Twelves CJ, Saltz LB, Haller DG, Sargent DJ. Impact of older age on the efficacy of newer adjuvant chemotherapies in $>12,500$ patients (pts) with stage II/III colon cancer: finding from the ASSENT database. J Clin Oncol. 2013:31:2600-6.

16. Lembersky BC, Wieand HS, Petrelli NJ, O'Connell MJ, Colangelo LH, Smith RE, Seay TE, Giquere JK, Marshall ME, Jacobs AD, Colman LK, Soran A, Yothers G, Wolmark N. Oral uracil and tegafur plus leucovorin compared with intravenous fluorouracil and leucovorin in stage II and III carcinoma of the colon: results from national surgical adjuvant breast and bowel project protocol C-06. J Clin Oncol. 2006:24:2059-64.

17. Twelves C, Wong A, Nowacki MP, Abt M, Burris 3rd H, Carrato A, Cassidy J, Cervantes A, Fagerberg J, Georgoulias V, Husseini F, Jodrell D, Koralewski P, Kröning H, Maroun J, Marschner N, McKendrick J, Pawlicki M, Rosso R, Schüller J, Seitz JF, Stabuc B, Tujakowski J, Van Hazel G, Zaluski J, Scheithauer W. Capecitabine as adjuvant treatment for stage III colon cancer. N Engl J Med. 2005;352:2696-704.

18. National Comprehensive Cancer Network. Bone Cancer (version 1.2014). http:// www.nccn.org/professionals/physician_gls/pdf/bone.pdf. Accessed 6 Feb 2014

19. Watanabe T, Itabashi M, Shimada Y, Tanaka S, Ito Y, Ajioka Y, Hamaguchi T, Hyodo I, Igarashi M, Ishida H, Ishihara S, Ishiguro M, Kanemitsu Y, Kokudo N, Muro K, Ochiai A, Oguchi M, Ohkura Y, Saito Y, Sakai Y, Ueno H, Yoshino T, Boku N, Fujimori T, Koinuma N, Morita T, Nishimura G, Sakata Y, Takahashi K, Tsuruta O, Yamaguchi T, Yoshida M, Yamaguchi N, Kotake K, Sugihara K, Japanese Society for Cancer of the Colon and Rectum. Japanese Society for Cancer of the Colon and Rectum (JSCCR) Guidelines 2014 for treatment of colorectal cancer. Int J Clin Oncol. 2015;20:207-39.

20. Tominaga T, Takeshita H, Arai J, Takagi K, Kunizaki M, To K, Abo T, Hidaka S, Nanashima A, Nagayasu T, Sawai T. Short-term outcomes of laparoscopic surgery for colorectal cancer in oldest-old patients. Dig Surg. 2015;32:32-8.

21. Ko JJ, Kennecke HF, Lim HJ, Renouf DJ, Gill S, Woods R, Speers C, Cheung WY. Reasons for underuse of adjuvant chemotherapy in elderly patients with stage III colon cancer. Clin Colorectal Cancer. 2016;15:179-85.

22. Popescu RA, Norman A, Ross PJ, Parikh B, Cunningham D. Adjuvant or palliative chemotherapy for colorectal cancer in patients 70 years or older. J Clin Oncol. 1999;17:2412-8

23. Brower M, Asbury R, Kramer Z, Pandya K, Bennett JM. Adjuvant chemotherapy for colorectal cancer in the elderly: population-based experience. J Clin Oncol. 1993:12:195-205.

24. Stein BN, Petrelli NJ, Douglass HO, Driscoll DL, Arcangeli G, Meropol NJ. Age and sex are independent predictors of 5-fluorouracil toxicity: analysis of a large scale phase III trial. Cancer. 1995;75:11-7.

25. Zalcberg J, Kerr D, Seymour L, Palmer M. Haematological and nonhaematological toxicity after 5-fluorouracil and leucovorin in patients with 
advanced colorectal cancer is significantly associated with gender, increasing age and cycle number. Eur J Cancer. 1998;34:1871-5.

26. Steinberg J, Erlichman C, Gadalla T, Fine S, Wong A. Prognostic factors in patients with metastatic colorectal cancer receiving 5 -fluorouracil and folinic acid. Eur J Cancer. 1992;28:1817-20.

27. Chiara S, Nobile MT, Vincenti M, Lionetto R, Gozza A, Barzaqcchi MC, Sanguineti O, Repetto L, Rosso R. Advanced colorectal cancer in the elderly: results of consecutive trials with 5-fluorouracil-based chemotherapy. Cancer Chemother Pharmacol. 1998:42:336-40.

28. Aschele C, Guglielmi A, Tixi LM, Bolli E, Mori AM, Lionetto R, Rosso R, Sobrero A. Adjuvant treatment of colorectal cancer in the elderly. Cancer Control. 1995;2 Suppl 1:36-8.

29. Fremgen AM, Bland KI, McGinnis Jr LS. Clinical highlights from the National Cancer Data Base. CA Cancer J Clin. 1999;49:145-58.

30. Gordon B. Data exchange standards and record description. Sacramento: North American Association of Central Cancer Registries; 1994. Standards for cancer registries.

31. Sanoff HK, Carpenter WR, Sturmer T, Goldberg RM, Martin CF, Fine JP, McCleary NJ, Meyerhardt JA, Niland J, Kahn KL, Schymura MJ, Schrag D. Effect of adjuvant chemotherapy on survival of patients with stage III colon cancer diagnosed after age 75 years. J Clin Oncol. 2012;30:2624-34.

32. Andre T, Boni C, Navarro M, Tabernero J, Hickish T, Topham C, Bonetti A, Clingan P, Bridgewater J, Rivera F, de Gramont A. Improved overall survival with oxaliplatin, fluorouracil, and leucovorin as adjuvant treatment in stage II or III colon cancer in the MOSAIC trial. J Clin Oncol. 2009;27:3109-16.

33. Goldberg RM, Sargent DJ, Morton RF, Fuchs CS, Ramanathan RK, Williamson SK, Findlay BP, Pitot HC, Alberts SR. A randomized controlled trial of fluorouracil plus leucovorin, irinotecan, and oxaliplatin combinations in patients with previously untreated metastatic colorectal cancer. J Clin Oncol. 2004;22:23-30.

34. Rothenberg ML, Oza AM, Bigelow RH, Berlin JD, Marshall JL, Ramanathan RK, Hart LL, Gupta S, Garay CA, Burger BG, Le Bail N, Haller DG. Superiority of oxaliplatin and fluorouracil-leucovorin compared with either therapy alone in patients with progressive colorectal cancer after irinotecan and fluorouracilleucovorin: interim results of a phase III trial. J Clin Oncol. 2003;21:2059-69.

35. Howlader N, Noone A, Krapcho M. SEER cancer statistics review. 1975-2008. http://seer.cancer.gov/csr/1975_2008/

36. Sanoff HK, Carpenter WR, Freburger J, Li L, Chen K, Zullig LL, Goldberg RM, Schymura MJ, Schrag D. Comparison of adverse events during 5 -fluorouracil versus 5 -fluorouracil/oxaliplatin adjuvant chemotherapy for stage III colon cancer: a population-based analysis. Cancer. 2012;1 18:4309-20.

37. Cen P, Liu C, Du XL. Comparison of toxicity profiles of fluorouracil versus oxaliplatin regimens in a large population-based cohort of elderly patients with colorectal cancer. Ann Oncol. 2012;23:1503-11.

38. Heijmen L, van Laarhoven HW, Punt CJ. Encouraging results in older patients receiving chemotherapy: a retrospective analysis of treatment guideline adherence in daily practice. Geriatr Gerontol Int. 2012;12:80-5.

39. Hu CY, Chan W, Delclos GP, Du XL. Adjuvant chemotherapy and risk of gastrointestinal, hematologic, and cardiac toxicities in elderly patients with stage III colon cancer. Am J Clin Oncol. 2012;35:228-36.

40. Chiang LY, Liu J, Flood KL, Carroll MB, Piccirillo JF, Stark S, Wang A, Wildes TM. Geriatric assessment as predictors of hospital readmission in older adults with cancer. J Geriatr Oncol. 2015;6:254-61.

41. Wildiers $H$, Heeren $P$, Puts $M$, Topinkova E, Lanssen-Heijnen ML, Extermann M, Falandry C, Artz A, Brain E, Colloca G, Flamaing J, Kaenakis T, Kenis C, Audisio RA, Mohile S, Repetto L, Van Leeuwen B, Milisen K, Hurria A. International society of geriatric oncology consensus on geriatric assessment in older patients with cancer. J Clin Oncol. 2014;32:2595-603.

42. Dale W, Mohile SG, Eldadah BA, Trimble EL, Schilsky RL, Cohen HJ, Muss HB, Schmader KE, Ferrell B, Extermann M, Nayfield SG, Hurria A, Cancer and Aging Research Group. Biological, clinical, and psychosocial correlates at the interface of cancer and aging research. J Natl Cancer Inst. 2012;104:581-9.

43. Hurria A, Mohil S, Gajra A, Klepin H, Muss H, Chapman A, Feng T, Smith D, Sun CL, Glas ND, Cohen HJ, Katheria V, Doan C, Zavala L, Levi A, Akiba C, Tew WP. Validation of a prediction tool for chemotherapy toxicity in older adults with cancer. J Clin Oncol. 2016; published online before print May 16.

\section{Submit your next manuscript to BioMed Central and we will help you at every step:}

- We accept pre-submission inquiries

- Our selector tool helps you to find the most relevant journal

- We provide round the clock customer support

- Convenient online submission

- Thorough peer review

- Inclusion in PubMed and all major indexing services

- Maximum visibility for your research

Submit your manuscript at www.biomedcentral.com/submit
() BioMed Central 